\title{
A Comparison of the Chinese and American Undergraduate Syllabi in Regard to Their Content and Style
}

\author{
Zhencong Liu; Tong Jia* \\ Beijing International Studies University
}

\begin{abstract}
This paper aims to compare the Chinese and American syllabi for undergraduates in regard to their content and style. 36 syllabi of various majors in different universities were collected and compared. It was found that the common components in both Chinese and American syllabi are heading, course introduction, course aim, course requirements, textbook, course plan, teaching methods, homework and assessment, etc. The special components for American syllabi are academic integrity and course evaluation. As for style, the American syllabi are more self-contained and resourceful than their counterparts. With higher standards, they are also more specific, operational and practical. Their teaching methods are more flexible and interactive. Their assessments are various, evenly distributing through the whole semester while the Chinese syllabi depend more on the final exam. The American undergraduate syllabi are more morality-oriented while their Chinese counterparts are more skill-driven.
\end{abstract}

Keywords—syllabus components; syllabus style; course syllabus; undergraduate syllabus; comparison of syllabi

\section{INTRODUCTION}

Originated from Greek (Liu, 2011), syllabus is an outline and summary of a certain course, including course introduction, instructor's contact information, course objective, teaching content, textbooks, reference books, class participation, scoring criteria and so on. Currently, research associated with syllabi has been done mainly in content, design, function, implementation, assessment and comparison of syllabi. As this paper was designed to compare the undergraduate syllabi of Chinese and American universities, studies related to other aspects of syllabi are not illustrated here.

There are not many studies concerning comparison and contrast of syllabi. Through comparing different countries' syllabi, scholars get a better and comprehensive understanding of syllabus. For instance, Zhao (2010) and Min (2011) illustrate practical and easily-implemented syllabus by analyzing American syllabi. In addition, some researchers (Fang, 2011a; Fang, 2011b; Zhu, 2010) have proposed some suggestions on the formulation of Chinese syllabi based on the study of differences of Chinese and American syllabi.

In a word, though studies on syllabi mainly focus on the theoretical level, those studies from the perspective of different universities and various majors are worth doing. Some studies tend to use case study, but the sample is not enough to be representative. Owing to this reason, this paper was designed to collect more representative syllabi to answer the following two questions:

1) What are the differences between Chinese and American undergraduate syllabi concerning content?

2) How do Chinese and American undergraduate syllabi differ in style?

\section{DATA COLLECTION}

The authors collected 36 course syllabi, including 18 Chinese syllabi and 18 American syllabi, most of which are of year 2012, together with some of year 2011, covering different universities, majors and subjects. Chinese undergraduate syllabi were collected through the Internet or with the help of the authors' colleagues, classmate and friends in universities outside China, while American undergraduate syllabi were collected mainly through the Internet, and most of them were available from the open courses of the university. After collecting all the needed syllabi, the authors numbered the data, and investigated the common components of them and further compared their differences. The sources of the collected syllabi can be seen in Table 1 and Table 2 
TABLE I CHINESE UNDERGRADUATE SYLLABI

\begin{tabular}{|l|l|l|}
\hline Course Name & University & Year \\
\hline Introduction to Communication Theory & University of Jinan & 2012 \\
\hline $\begin{array}{l}\text { Practical Training and Exercise Optical } \\
\text { Communication and Integrated Optoelectronics }\end{array}$ & Zhejiang University & 2011 \\
\hline Analogue Electronic Circuits & Harbin Engineering University & 2012 \\
\hline Politics & Huashang College Guangdong University of Finance and Economics & 2011 \\
\hline International Business Law & Shanghai University of International Business and Economics & 2011 \\
\hline Introduction to Economic Law & Beijing University of Chinese Medicine & 2011 \\
\hline Structural Chemistry & Nanjing Normal University & 2012 \\
\hline Molecular Biology & Chongqing University of Technology & 2011 \\
\hline Medical Microbiology & Hetao University & 2012 \\
\hline Environmental History of China & Sun Yat-Sen University & 2011 \\
\hline Introduction to Chinese Civilization & Yantai University & 2011 \\
\hline Environmental Biology & Liaocheng University & 2016 \\
\hline Material Physics & Central South University & 2012 \\
\hline Mathematical Analysis & Zhejiang University & 2011 \\
\hline Mathematical Software & Beijing Normal University & 2012 \\
\hline Interpretation & Lishui University & 2012 \\
\hline Second Foreign Language---Japanese & Xinzhou Teachers University & 2012 \\
\hline British and American Literature & North West Agriculture and Forestry University & 2011 \\
\hline
\end{tabular}

TABLE II AMERICAN UNDERGRADUATE SYLLABI

\begin{tabular}{|l|l|l|}
\hline Course Name & University & Year \\
\hline $\begin{array}{l}\text { Introduction to Political Science Research } \\
\text { Methods }\end{array}$ & Harvard University & 2011 \\
\hline Ethical Issues in Clinical Research & Northwestern University & 2011 \\
\hline Constitutional Law & Yale University & 2011 \\
\hline Italy since 1815 & New York University & 2010 \\
\hline Introduction to the Earth System & Konell University & 2012 \\
\hline Computer Methods for Historical Analysis & Harvard University & 2011 \\
\hline Japanese 1 & MIT & 2011 \\
\hline English 42: Arrivals & Harvard University & 2011 \\
\hline Translating East Asia & Princeton University & 2012 \\
\hline Structural Equation Modeling & Princeton University & 2012 \\
\hline Math 31L & Duke University & 2012 \\
\hline SEC Syllabus (2012): Physics & California Institute of Technology & 2012 \\
\hline Vertebrate Biology, Biology 452 & Washington University & 2012 \\
\hline Chemistry & Yale University & 2011 \\
\hline Organic Chemistry & Harvard University & 2011 \\
\hline
\end{tabular}




\begin{tabular}{|l|l|l|}
\hline \multicolumn{2}{|c|}{ TABLE 2, cont. } & 2012 \\
\hline CS242: Programming Studio & Illinois University, Champaign & 2012 \\
\hline $\begin{array}{l}\text { Communication in the Electronic Age (COM } \\
\text { 394) }\end{array}$ & Arizona State University & 2012 \\
\hline Circuits and Electronics & MIT & 2 \\
\hline
\end{tabular}

\section{FINDINGS AND DISCUSSION}

Candlin (1984: 31) held that course syllabus is a summative description of language learning, including learning objective, leaning experience, learning assessment and the roles of teacher and students. What's more, according to Dai (2009: 3), a comprehensive course syllabus should contain teaching objectives, teaching content, teaching sequence, teaching method and assessment. Likewise, Davis (2006: 12) thought that a comprehensive course syllabus should consist of course introduction, instructor's contact information, course requirements, course objective, course structure, teaching method, textbook, reading materials, assignment, course schedule and so on.
Candlin provided a broad range of course syllabus, while Dai further specified the components of course syllabus. Moreover, as for the range of course and the components of course syllabus, the authors share a similar opinion with Davis (2006).

\section{a) Differences of Components in Chinese and American Undergraduate Syllabi}

Through analyzing both American and Chinese undergraduate syllabi, the main common components are headings, course objective, course requirements, textbook, course plan, teaching method, assignment and grading, while some syllabi even contain prerequisites, course overview, and course evaluation. The specific components of syllabus can be seen in Table 3 .

TABLE III COMPONENTS OF CHINESE AND AMERICAN UNDERGRADUATE SYLLABI

\begin{tabular}{|c|c|c|c|c|c|c|c|c|c|c|c|}
\hline & $\begin{array}{c}\text { head- } \\
\text { ing }\end{array}$ & $\begin{array}{c}\text { over } \\
\text {-view }\end{array}$ & $\begin{array}{c}\text { objecti } \\
\text { ve }\end{array}$ & $\begin{array}{c}\text { require-m } \\
\text { ents }\end{array}$ & $\begin{array}{c}\text { text- } \\
\text { book }\end{array}$ & $\begin{array}{c}\text { teaching } \\
\text { plan }\end{array}$ & $\begin{array}{c}\text { teaching } \\
\text { method }\end{array}$ & $\begin{array}{c}\text { assign- } \\
\text { ment }\end{array}$ & $\begin{array}{c}\text { grad } \\
\text { ing }\end{array}$ & prerequisites & $\begin{array}{c}\text { academic } \\
\text { integrity }\end{array}$ \\
\hline $\begin{array}{c}\text { Chinese } \\
\text { Syllabi }\end{array}$ & 15 & 2 & 16 & 14 & 16 & 15 & 11 & 8 & 15 & 10 & 0 \\
\hline $\begin{array}{c}\text { American } \\
\text { Syllabi }\end{array}$ & 17 & 14 & 11 & 16 & 16 & 15 & 18 & 17 & 18 & 4 & 5 \\
\hline
\end{tabular}

In contrast, Chinese syllabi seldom contain course overview, academic integrity and course evaluation. Meanwhile, prerequisites are not an indispensable part in American syllabi. However, academic integrity and course evaluation only exist in American syllabus, which means academic integrity plays an important role in America and it is a guideline for academy, so every student must follow this principle.

\section{1) Headings}

Headings are the main components of both American and Chinese syllabi. Generally speaking, the heading introduces the basic information of the course, and is made up of the course name, the semester, the location of the class, the instructor and the contact information of the instructor. The following is an example of Ethical Issues in Clinical Research of Northwestern University.

Time: Wednesday afternoons, 6:00-7:30 p.m.

September 21-December 7, 2011

Location: McGaw 2-403
Course Directors:

Maureen Moran, MPH
Assistant Professor of Preventive

Medicine

(312) 503-0500

m-moran@northwestern. Edu

Peter Orris, MD, MPH

Adjunct Professor of Preventive Medicine

(312)864-5220

porris@uic.edu

Office Hours: By appointment

(Maureen, 2011)

The headings of Chinese syllabi contain course code, course name, English course name, credits, lecture time, prerequisites and editor of the course. The environmental biology of Liaocheng University is as follows: 
Course code: 14422401

English course name: environmental biology

Type of course: compulsory course

Credit hours: 64

Credits: 4

Prerequisites: introduction to environmentology, environmental microbiology and so on

Editor: Zhang Jinping

(Yao, 2012)

In contrast, the headings of Chinese syllabi are more specific, which contain something that American syllabi do not cover. However, the headings of Chinese syllabi ignore the contact information of the instructor. This fact reflects the tendency that Chinese syllabi are designed for the authorities, while American syllabi for the students.

\section{2) Overviews}

Sometimes, the overview part of the syllabus is called "course description", "course intentions" and "course rationale". Course overviews often introduce the basic information of the course, what to be taught in the course and what to be acquired during the study in general and also about the schedule of the course. See another example of Introduction to the Earth System of Konell University.

This course explores the history and theory of the modern rights regime. We will start with the present conundrum of human rights: a surfeit of human rights law, nationally and internationally, and an actual lack of rights for individuals and people; the proliferation of humanitarian activism and the suspicion that it will not alleviate misery and provide succor. The discussion of the present will lead us to wonder when, where, and for whom human rights and, for that matter, humanitarianism provide actual solutions to real-life problems-and what these problems might be. We will also explore the passions that motivated people to pursue human rights and the empathy that led them to uproot injustice-and what this passion did and did not achieve. The revolutionary challenges to national and international society in the late eighteenth and in the mid twentieth century will be the two pivots of this inquiry. But we will also spend a good deal of time wondering about the curious absence of human rights in the midst of the proliferation of humanitarian good will in moments of high imperialism. And nowadays we need to be concerned once again with those moments of ill will, when even humanitarianism is failing. This, in turn, will give us plenty of material to return to the present and to come to some informed conclusions, where we stand today in terms of human rights.

Geyer (2011).

\section{3) Course Objective}

Course objective sometimes is listed below the course introduction, but sometimes it is separate. Course objective aims to inform the students of the acquisition during the course after a semester.

\section{4) Course requirements}

Course requirements are some demands that students must conform to. Course requirements consist of the requirements of attendance, assignment, evaluation and so on Course requirements are the main components of the syllabi. The course requirements of American syllabi are more specific, while Chinese ones are more general. In addition, reading assignment is also included in the course requirements of American syllabi. Usually, students are required to read two chapters for every class, and some other classes will need extra reading.

\section{5) Textbooks}

Generally speaking, textbooks are mainly divided into three kinds, required textbooks, further readings or suggested textbooks and journals or articles. Sometimes the instructors assign some readings through the Internet, with the form of articles, cases or handouts online. Chinese students are required to use textbooks only. Compared with Chinese students, American students have more choices concerning course materials. For example, they use textbooks, journals, handouts and other kinds of materials. Furthermore, the resources that American students use are more up to date. The following is an example of organic chemistry of Harvard University.

BOOKS (available at the Harvard Coop or at FlashPrint as listed below):

Required: Organic Chemistry, G. Marc London. Fourth or Fifth Edition (available at the Coop)

Molecular model kit (any one is fine; they sell them at the Coop).

The Organic Chem Lab Survial Manual, James Zubrick (any recent edition is fine; Coop)

Blank laboratory notebook with duplicate pages (Coop)

Chen S-20 Lab Manual available at FlashPrint, 99 Mt. Auburn St. in Harvard Square 
Recommended: Organic Chemistry as a Second Language, Vol. I, David R. Kleun (Coop)

Study guide and solutions manual for London, Organic Chemistry

(Logan \& Melissa, 2011)

\section{6) Course Plan}

Course plan includes the teaching schedule of the whole semester, such as teaching content, reading lists or keywords. The results show that course plan is also the main component of the syllabus. The following is an example of translating East Asia of Princeton University for 2012.

\section{Syllabus}

Week 1 (2/7): The First Chapter of the Second-Most Translated Book in the World

175 translations of the Daodejing:

http://www.bopsecrets.org/gateway/passages/tao-te-chi ng.htm

Week 2 (2/14): Thinking about Translation

Walter Benjamin, "The Task of the Translator"

Naoki Sakai, Translation and Subjectivity, 1-39

Jacques Derrida, "Des Tours de Babel"

Lydia Liu, Translingual Practice: Literature,

National Culture, and

Translated Modernity —China, 1900-1937, 1-42

(Kevin, 2012)

\section{7) Teaching method}

As an important component of syllabus, teaching method can guide the instructor to be well-prepared for the class while helping the students to cooperate easily with their instructors. Therefore, teaching method plays a vital role in the process of teaching and learning. American syllabi list more teaching methods, which are more detailed. Teaching methods in American syllabi are more diverse, including case study and seminar, etc.

On the other hand, Chinese syllabi list fewer teaching methods than American syllabi, mainly employing lectures. In addition, other frequently used teaching methods are class discussion, internship and so on.

\section{8) Assignments}

There are two kinds of assignments, individual assignments and group assignments. Group assignments usually involve teamwork, group discussions, etc. As for the form of assignments, American syllabi list more types of assignments, such as presentations, reading reports, reading journals, quizzes and papers. American students receive assignments nearly every class, so their academic pressure is huge, while they have no final examination. Therefore, their final scores depend on their usual performance. It appears that the variety, depth, and difficulty of assignments listed on the Chinese syllabi should be improved.

\section{9) Grading}

Grading is clearly listed in most of the syllabi, implying that great importance is attached to the learning outcome of students in both Chinese and American education. As a whole, the methods of grading in American syllabi are more various and the weight is distributed rather evenly throughout the whole semester. The syllabus of Organic Chemistry of Harvard University for 2011 is shown as below.

\section{EXAMINATIONS AND GRADING:}

Your grade will be based on:

Top 5 Hour Exams $\quad 50 \%$

Final Exam $\quad 30 \%$

Lab $20 \%$

There will be no makeup examinations for the exams; we will drop your lowest exam (or one missed exam). This course is not graded on a curve; we will use the following scale to assign letter grades:

85-100 70-85 55-70 50-55 below 50

A- or A B-. B, or B+ C-, C, or C+ D $\quad$ F The cutoffs for the + and - grades are left to our discretion.

(Logan \& Melissa, 2011)

10) prerequisites and preassignments

Prerequisites refer to requirements that the students must meet before choosing the course. Chinese syllabi have more specific requirements, indicating that Chinese syllabi emphasize the continuity of courses. The following is an example of Structural Equation Modeling of Princeton University for 2011.

\section{Prerequisites}

It is expected that students have had both a basic statistics course and a course covering multiple regression (e.g., SOC 504). Familiarity with matrix algebra is also required. We will review matrix algebra, but the course will use matrix algebra extensively, so some level of comfort working with matrices is necessary.

(Lynch, 2011) 


\section{1) academic integrity}

Academic integrity is also called "honor code" or "honor policy". It is aimed to emphasize the standard of academic integrity. For example, all the assignment should be done by students themselves and if violated, students will receive punishment. Few Chinese syllabi have this part. The example of Programming Studio is illustrated as follows.

\section{Plagiarism/Academic Honesty}

- We expect you to properly cite all sources that you use to complete an assignment.

- Each week, we will be running your code through automated software to check for any cases of academic dishonesty.

- The first violation will result in a non-droppable zero on the assignment, the second will result in failing the course, any subsequent violations will be taken up by the college up to possible dismissal from the university.

This policy holds regardless of when the dishonesty is detected. (Woodley, 2012)

\section{2) Course evaluation}

Course evaluation usually is implemented through the Internet, including the evaluation of the course and the instructor of the course. Students evaluate the course anonymously. Only after the students finish the evaluation can they see their grades in the teaching system. The following example is from Ethical Issues in Clinical Research of Northwestern University.

\section{Course Evaluation}

The MPH Program administers web-based course evaluations to students for each course near the end of the quarter. Your completion of both the Unit (course) and Faculty evaluations is required; failure to complete the evaluations will result in an incomplete grade until the evaluations are submitted. You will be sent the web link and instructions via e-mail later in the quarter. You will have several weeks to complete the evaluations before grades are submitted. Your evaluation of the course and faculty is anonymous; your identity can not be linked with your responses.

(Maureen, 2011)

\section{THE DIFFERENCES OF STYLES OF AMERICAN AND CHINESE} SYLLABI

In terms of stylistic features, American syllabi form a comprehensive net of syllabi, while Chinese syllabi are general, lacking other means of support. American syllabi contain rich content and are easy to operate; however, Chinese syllabi are too general to be taken into action. With a strict standard and a goal of cultivating students' ability to practice, American syllabi pay more attention to practice, while Chinese syllabi give priority to the teaching of theory and knowledge. With the help of various teaching methods and interaction between instructors and students, American syllabi emphasize students' daily performance; however, Chinese syllabi mostly specify final examination as the way of grading. American syllabi tend to teach students how to do things and gain some useful lessons of life, while Chinese syllabi are inclined to teach students the skills of doing things.

Firstly, American syllabi are systematic, because it can be seen easily from the components of the syllabi. Together with other resources, American syllabi can better serve their purposes. On the other hand, Chinese syllabi are not clear enough to give students specific guidelines. Half of the collected Chinese syllabi do not list the credits, teaching method and other parts. Chinese students have limited access to learning resources (Zhu, 2010; Zhao, 2010).

Secondly, American syllabi specify the teaching content and assignments, which seems to be clear for students to follow. As for Chinese syllabi, the description of assignments just covers several words, which seems a little difficult for students to comprehend and follow. American syllabi have strict standards for students while Chinese syllabi propose relatively lower standards for students. Generally speaking, American students have more reading tasks than Chinese students.

Thirdly, American syllabi focus on cultivating students' abilty; however, Chinese syllabi give priority to theoretical teaching. Teaching methods differ in the two countries: American syllabi tend to combine different kinds of teaching methods to train students' integrated abilities, but Chinese syllabi often ignore the interaction between students and instructors. American syllabi have more than one way to assess students' performances during the whole semester, but Chinese syllabi put most of the emphasis on the final examination.

Finally, American syllabi do not only involve theoretical teaching, but also pay attention to cultivating students' characters. American syllabi sometimes focus on cultivating students' interests. On the contrary, Chinese syllabi always concentrate on the teaching of skills, failing to demonstrate the advanced teaching philosophy and characteristics of teachers (Fang, 2010a; Zhao, 2010).

\section{CONCLUSION}

Through the analysis of American and Chinese undergraduate syllabi, it can be easily found that American syllabi always list the free time of the instructors, while 
Chinese syllabi seldom mention that. Another big difference lies in the requirement of academic integrity, which further reflects the issue of intellectual property in America. In terms of Chinese syllabi, instructors should utilize every teaching method to encourage students to participate actively in daily teaching and learning. At the same time, the assignments should be designed properly and arranged evenly in the whole semester so that students can take more responsibility with their study and make the most of the syllabus.

\section{REFERENCES}

[1] Candlin, C. N. (1984). Implementing process curricula in ESL: The issue of "task". Paper presented at the 8th annual TESOL conversation, Houston, TX.

[2] Dai, W. (2009). Foreign language teaching of Chinese colleges in 30 years. Foreign Language World(1): 2-4. (in Chinese)

[3] Davis, B. G. (2006). Tools for Teaching. Hangzhou: Zhejiang University Press.

[4] Fang, H. (2011a). A study of American college syllabus. Journal of Changchun University of Technology (Higher Education Study Edition)(2):142-144. (in Chinese)

[5] Fang, H. (2011b). Syllabus analysis of Sino-US higher pedagogy major-Taking Fujian Normal University and Pennsylvania State University for example. Journal of Hubei University of Education(28): 85-86. (in Chinese)

[6] Geyer, M. (2011). Earth System, Konell University. http: //humanrights.uchicago.edu/curriculumdevelopmets/syllabi/UChicago /Geyer\%20HR2\%20211 (accessed 13/11/2011)
[7] Kevin, M. (2012). Translating East Asia, Princeton University. https://www.princeton.edu/eas/undergraduate/courses/ (n.d.)

[8] Liu, W. (2011). A research of lessons in worldwide English teaching. Foreign Language World(4): 18-28. (in Chinese)

[9] Logan, M. \& Melissa, G. (2011). Organic Chemistry, Harvard University. http://isties/harvard.edu/fs/docs/icb.topic918017.files/Chem\%20S202011\%20syllabus.pdf (accessed 1/11/2011).

[10] Lynch, S M. (2011). Structural Equation Modeling, Princeton University.

http://www.princeton.edu/ slynch/soc590/sem11syllabus.pdf (accessed 31/7/2012).

[11] Maureen, M. (2011). Ethical Issues in Clinical Research, Northwestern University. http: Publichealth.northwestern.edu/current-students/Course\%20Syllabui/ MPH/PH441Fall_2011.pdf. (accessed 7/11/2011)

[12] Min, L. (2011). Deigning and carrying out a course syllabus---Exemplified by sociolinguistics of English Department at the City University of New York. Journal of Hainan Radio \& TV University(4): 118-121. (in Chinese)

[13] Woodley, M. (2012). Programming Studio, Illinois University https://wiki.engr.illinois.edu/display/cs242sp12/Syllabus (accessed 17/7/2012)

[14] Yao, X.(2012). Environmental Biology, Liaocheng University. http://hjxy.lcu.edu.cn/content/2816.html. (n.d.)

[15] Zhao, Y. (2010). American college course syllabus. Education Teaching Research (5): 163-164. (in Chinese)

[16] Zhu, J. (2010). The designing and implementation of syllabi in higher institutions. Social Science Front (1): 276-277. (in Chinese). 